\title{
Simplified Casing Program for Development Wells in Mahu Well Block
}

\author{
Zongyu Lu ${ }^{1}$, Weifeng Chen ${ }^{1}$, Sihao $\mathrm{Li}^{2}$, and Yingjin Zhang ${ }^{2, a}$ \\ ${ }^{1}$ Engineering and Technology Research Institute of Xinjiang Oil Field Co, Karamay 834000, China \\ ${ }^{2}$ National Engineering Laboratory of Petroleum Drilling Technology, Leak Resistance \& Sealing Technology Research Department, Yangtze \\ University, Wuhan 430100, China
}

\begin{abstract}
In the Mahu well block of Junggar basin, the complex formation has many sets of pressure system. Especially, the formation with microcracks in the middle layer is loose and the pressure bearing capacity is low. Lost circulation is prone to occur in this layer. At present, high investment and long drilling period were the main problems in the exploration and development process. The geostress 3D model of Mahu well block was established by means of logging and drilling data. The model provided the three-pressure profiles of Mahu well block for casing program optimization and safety drilling. Each well could be optimized the intermediate casing setting position. The intermediate casing was saved 160 meters long. The total of drilling speed was improved 5 times compared with the past drilling process. Slim hole drilling technology raised ROP $51.96 \%$ higher, and the average drilling period is shorten to 24.83 days.
\end{abstract}

\section{Introduction}

Mahu well block with complex lithology in Xinjiang Junggar basin of China is a new oil \& gas reserves and production oilfield. The important technical items for development wells are focused in the simplifying casing program. There are many sets of pressure system, and the middle layer contains microcracks. The sandstone layer is the loose conglomerate cementation, which has a weak capacity of bearing pressure. The drilling wells is prone to leakage[1,2]. There are thick gravel layers in the deep strata. The rock strength is higher and the rate of penetration (ROP) is low. The pressure coefficient of the abnormally high-pressure formations was 1.74 , such as the Triassic Bkq Formation. The well control risks are higher. The above factors lead to the Mahu well block drilling process are being the situations of difficulty, high risk and long period[3].

In order to reduce the cost, the study of simplifying casing program was carried out by choosing the right drill bit and drilling fluid system. A reasonable casing program for the well block was formed, which avoided lost circulation, well blowout, borehole collapse, pipe sticking and other engineering accidents. The smoothly safety of drilling operations reduced significantly the project costs[4].

\section{Influencing factors of casing program design}

\subsection{Stratigraphic lithology}

In the past, during drilling operation, lost circulation in the Jurassic Bdw formation and Triassic Bjt formation in Mahu well block had been occured. The main reason is that the Jurassic Bdw formation contains a large number of microcracks, and that the bottom formation of the conglomerate layer is loose. Although the lithology of the Bjt formation is dominated by mudstone, the layer's is low, because there are two sets of sandstone layers at the top and middle location[5].

\subsection{Formation pressure evaluation}

\subsubsection{Formation pore pressure}

The pore pressure in Mahu well block is analysed by the theory of undercompaction according to logging data[6]. The pore pressure is almost identical to each well. The strata above Triassic are the normal pressure system. Triassic Bjt formation is a pressure transition zone. The formation from Triassic Krmy to Bkq is an abnormally high-pressure layer. The target layer pore pressure of Bkq formation is differences. The pore pressure equivalent density is between $1.40 \mathrm{~g} / \mathrm{cm}^{3} \sim 1.75 \mathrm{~g} / \mathrm{cm}^{3}$. The $\mathrm{Bkq}$ formation was prone to overflow, well-kick and other complex conditions during drilling well[7].

\subsubsection{Formation fracture pressure}

The minimum horizontal principal stress can be used as a fracture pressure, especially for fractured formation [8-10]. The minimum horizontal principal stress model of Mahu

${ }^{a}$ Corresponding author: zhangyingjin@ yangtzeu.edu.cn 
well block is established by the geostress model combined the well logging method with the effective stress ratio method.

There is a low-fracture-pressure condition in the bottom formation of the Jurassic Bdw and the Bjt formation. The equivalent density of the minimum horizontal principal stress is about $1.50 \mathrm{~g} / \mathrm{cm}^{3}$. In Cretaceous and Triassic strata, the minimum horizontal principal stress is relatively high, and equivalent density of Bkq formation is $1.70 \mathrm{~g} / \mathrm{cm}^{3} \sim 1.90 \mathrm{~g} / \mathrm{cm}^{3}$.

\subsubsection{Three formation pressure profiles}

The three-pressure profiles of Mahu well block were established by well logging, mud logging and drilling data[11].

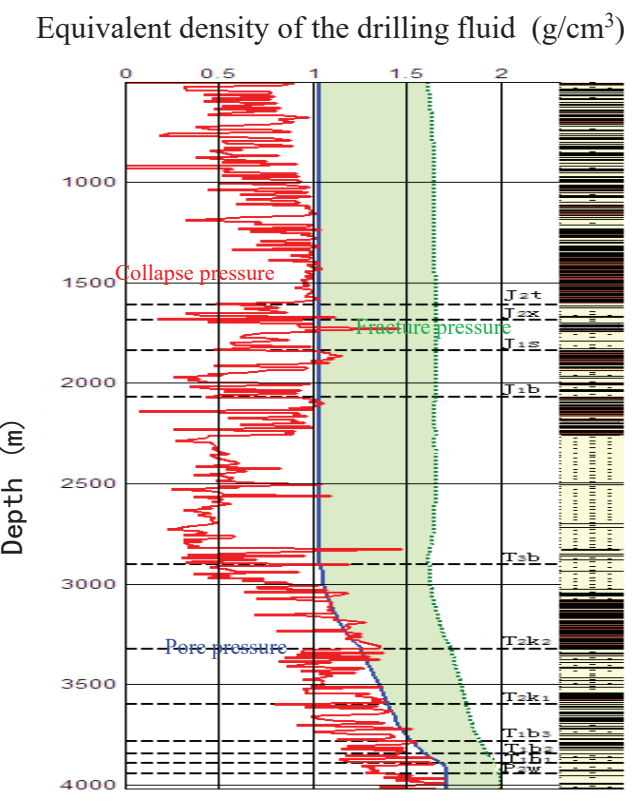

Figure 1. Three-pressure profiles of Mahu well block

From figure 1, the strata above Triassic are normal pressure system, and the formation from Triassic Krmy to Bkq formation is an abnormal high-pressure stratigraphy, which is very prone to well-kick, overflow and even more seriously complex situations[12]. The strata above the Jurassic Bdw formation are dominated by sandstonemudstone. The collapse pressure is increasing according to the well depth. The borehole wall stability is weakened. The stability of the wellbore at the bottom of the Bdw formation is stabilized. The collapse pressure of Triassic strata formation is synchronized with the increase in formation pore pressure. The security density window of Triassic formation narrows gradually, especially the security density window in the lower strata of the Triassic $\mathrm{Bkq}$ formation is the smallest (Figure 1).

\subsection{Rock mechanics characteristic}

The rock mechanical characteristic profiles Mahu well block[13] are set up. The rock mechanical parameters of stratum are fluctuated greatly because of the varied lithology (Table 1).

Table 1. Rock mechanical parameters

\begin{tabular}{|c|c|c|c|c|}
\hline $\begin{array}{c}\text { Forma- } \\
\text { tion }\end{array}$ & $\begin{array}{c}\text { Compressive } \\
\text { strength } \\
\mathbf{M P a}\end{array}$ & $\begin{array}{c}\text { Internal } \\
\text { friction } \\
\text { angle }\end{array}$ & $\begin{array}{c}\text { PDC bit } \\
\text { drillability }\end{array}$ & $\begin{array}{c}\text { Cone } \\
\text { bit } \\
\text { drillab- } \\
\text { ility }\end{array}$ \\
\hline $\mathrm{Tgl}$ & $10 \sim 50$ & $26 \sim 38$ & $0.5 \sim 3.5$ & $0.5 \sim 6$ \\
\hline $\mathrm{Bdw}$ & $60 \sim 90$ & $38 \sim 41$ & $5 \sim 9$ & $5 \sim 9$ \\
\hline $\mathrm{Bjt}$ & $20 \sim 40$ & $38 \sim 32$ & $2 \sim 4$ & $4 \sim 6$ \\
\hline $\mathrm{Krmy}$ & $30 \sim 60$ & $35 \sim 38$ & $3 \sim 4.5$ & $5 \sim 7$ \\
\hline $\mathrm{Bkq}$ & $25 \sim 70$ & $35 \sim 43$ & $3.2 \sim 4.5$ & $3.8 \sim 8$ \\
\hline
\end{tabular}

\section{Disadvantage of previous casing program}

\subsection{Difficult points in drilling operation}

From the formation pressure and rock mechanical characteristic, the difficulties during drilling engineering in Mahu well block are the following:

- The Jurassic and Triassic formation are prone to lost circulation, pipe sticking and other complex situations;

- The target layer of Bkq formation is an abnormally high-pressure formation. The security drilling fluid density window is narrow and the drilling fluid type is difficult to optimize.

- The bottom of Jurassic system is a set of thick gravel beds. The rock strength is grave. The bit optimization is difficult.

- The low drilling speed of previous wells restricts the economical and efficient development of Mahu well block.

\subsection{Present situation of casing program}

Before 2016, the main third spud section structure is shown in Table 2. The previous casing program has the following problems:

- The middle-deep wells with the normal pore pressure system formation, three-spudding casing program was too single. The drilling speed is too slow to reduce drilling costs.

- The bit type was almost cone bit, which was not better adapt to the underground environment. The drilling complex situations was prone to provide lower penetration.

- The improper handling method of drilling fluid was prone to leakage and other complex collapse conditions. 
Table 2. Present situation of casing program.

\begin{tabular}{|c|c|c|c|c|}
\hline Spudding & $\begin{array}{c}\text { Bit } \\
\text { diameter } \\
\text { (mm) }\end{array}$ & $\begin{array}{c}\text { Drilling } \\
\text { depth } \\
\text { (m) }\end{array}$ & $\begin{array}{c}\text { Casing } \\
\text { diameter } \\
\text { (mm) }\end{array}$ & $\begin{array}{c}\text { Casing } \\
\text { depth } \\
\text { (m) }\end{array}$ \\
\hline First & 444.5 & 500 & 339.73 & 500 \\
\hline Second & 311.15 & 3140 & 244.84 & 3140 \\
\hline Third & 215.9 & $\begin{array}{c}\text { Design } \\
\text { depth }\end{array}$ & 139.7 & $\begin{array}{c}\text { Design } \\
\text { depth }\end{array}$ \\
\hline
\end{tabular}

\section{Optimized casing program}

The casing program of oil production wells was optimized from conventional-size three-spudding structure to slim hole three-spudding structure. The horizontal wells adopted slim hole three-spudding structure, and the completion method of horizontal wells was simplified(Figure 2). Anti-sloughing drilling fluid system was adopted to the formation characteristics of the Mahu well block for safe and efficient drilling operation.

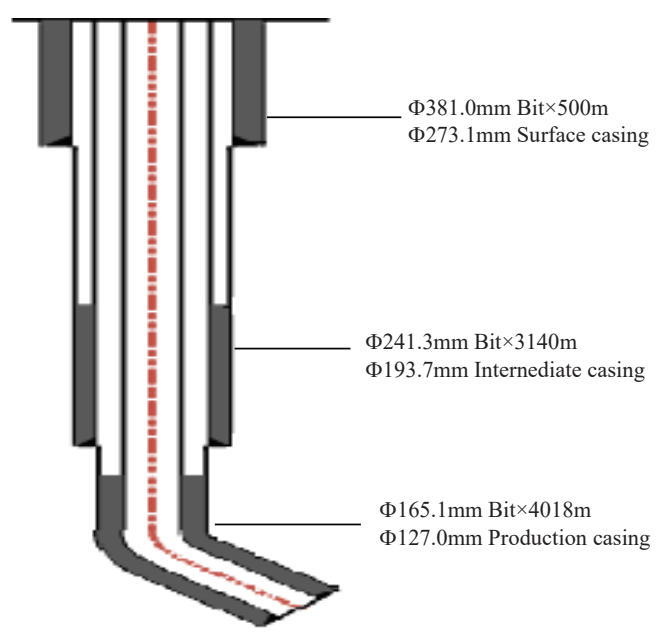

Figure 2. Casing program of straight well/directional well

Figure 2 shows the slim hole three-spudding structure of oil production wells. First spudding is designed to seal the superficial layer for refrainment from the loosed and collapsed formation, and for equipment the well-control blowout preventer on the wellhead. Second spudding is designed to seal two sets of pore pressure system in the corresponding well section. The cement slurry is back to the depth of $2540 \mathrm{~m}$. Third spudding is designed to create safety drilling conditions. The cement slurry is back to the depth of $3276 \mathrm{~m}$.

\section{Matching technology for the optimized casing program}

\subsection{Anti-sloughing drilling fluids}

The experimental analysis of hydration swelling indicated that the unstable layers of the Mahu well block are Sgh formation, Bjt formation, Krmy formation and Bkq formation. The rock sample has the same linear expansion rate in 2 hours as the bentonite in 16 hours.
The low rate of rock expansion shows that the rock is unstable when it touches water. That is to say, the initial expansion is faster, but the hydration expansion will gradually slow down. Clay minerals in Mahu well block contain the weak swelling ingredient. A large number of strong water sensitive disperse minerals in rock sample is lower. The linear swelling rate of rock sample is low, but the roller recovery is low too. The formation belongs to weak expansion and strongly dispersed layer. Drilling fluid should be optimized to improve the ability of restraining dispersion for the expansion formation.

The synergistic inhibition of drilling fluid system can be enhanced the ability of restraining dispersion for the expansion formation by triadic coordination inhibitor. The average roller recovery of the ternary synergistic controlled drilling fluid system has been improved to about $90 \%$. The inhibition of hydration swelling in the sediments of the Mahu well block is not obvious. This is mainly related to the hydrodynamic characteristics of the volcanic strata $[14,15]$. (Table 3 )

Table 3. Ternary synergistic suppression water-based drilling fluid preferred formula

\begin{tabular}{|c|c|}
\hline $\begin{array}{l}\text { Recipe } \\
\text { number }\end{array}$ & Formula \\
\hline M-3-1 & $\begin{array}{l}4 \% \text { Soil pulp }+0.3 \% \text { FA367+2\% SMP- } 2+2 \% \\
\text { SPNH }+1 \% \text { Redu } 1+0.3 \% \mathrm{CaO}+0.3 \% \mathrm{KOH}+ \\
10 \% \text { OS- } 80+1 \% \text { SIAT }+3 \% \mathrm{KCl}+4 \% \mathrm{PHT}+1 \% \\
\text { Graphite powder }+ \text { Barite }\end{array}$ \\
\hline M-3-2 & $\begin{array}{l}4 \% \text { Soil pulp }+0.3 \% \mathrm{FA} 367+2 \% \mathrm{SMP}-2+2 \% \\
\mathrm{SPNH}+1 \% \text { Redu } 1+0.3 \% \mathrm{CaO}+0.3 \% \mathrm{KOH} \\
+10 \% \text { OS- } 80+1 \% \mathrm{MFG}+3 \% \mathrm{KCl}+4 \% \mathrm{PHT}+1 \% \\
\text { Graphite powder }+ \text { Barite }\end{array}$ \\
\hline M-3-1 & $\begin{array}{l}4 \% \text { Soil pulp }+0.3 \% \mathrm{FA} 367+2 \% \mathrm{SMP}-2+2 \% \\
\mathrm{SPNH}+1 \% \text { Redu } 1+0.3 \% \mathrm{CaO}+0.3 \% \mathrm{KOH} \\
+10 \% \text { OS- } 80+1 \% \mathrm{JXL}-\mathrm{B}+3 \% \mathrm{KCl}+4 \% \mathrm{PHT} \\
+1 \% \text { Graphite powder }+ \text { Barite }\end{array}$ \\
\hline
\end{tabular}

\subsection{Bit optimization}

Rock mechanics is the main factor affected the rock breaking efficiency. According to the established rock mechanical characteristics section (Table 1), the sizes and types bit series for Mahu well block is optimized. The optimization method is combined the drilling bit optimization model with the best efficiency drill bit used in the reference area. Table 4 show rsults of bit optimization for Mahu well block.

Table 4. Results of bit optimization

\begin{tabular}{|c|l|}
\hline Spudding & \multicolumn{1}{|c|}{ Recommended bit type } \\
\hline First & ST115G,SKG124 \\
\hline Second & $\begin{array}{l}\text { FX56DX3(DBS), SF56H3(DBS), } \\
\text { S519, MS1952SS, FR1965, M935T }\end{array}$ \\
\hline Third & $\begin{array}{l}\text { SF54VH3(DBS), SF44VH3(DBS), } \\
\text { FR1643S, MS1643SS, BTM115AE }\end{array}$ \\
\hline
\end{tabular}

\subsection{Application of simplified casing program}

The effect of the casing program optimization and the increasing drilling speed technology is remarkable on the 
slim hole drilling in Mahu well block. The slim hole average ROP was $8.13 \mathrm{~m} / \mathrm{h}$, increased $51.96 \%$ compared to the previous wells. The average drilling period of the slim hole was 55.7days, saved 24.83days than the previous wells. (Table 5)

Table 5. Comparison of optimization effects

\begin{tabular}{|l|c|c|}
\hline & $\begin{array}{c}\text { Drilling period } \\
\text { (d) }\end{array}$ & $\begin{array}{c}\text { Average ROP } \\
(\mathbf{m} / \mathbf{h})\end{array}$ \\
\hline Previous wells & 80.53 & 5.53 \\
\hline Slim hole wells & 55.7 & 8.13 \\
\hline
\end{tabular}

\section{Conclusions}

According to the bottom of Jurassic and Triassic leakage and deep mudstone sloughing characteristics, the main ideas are to prevent leakage, control formation dispersion and expansion, and realize the safety drilling. The ternary synergistic suppression drilling fluid system is proposed. The system combines with three steps of hydrationphysical, chemical plugging and stress support. Jurassic formation is characterized by deep grey and gray silty mudstone. The rigid PDC drill with 5 blades and $16 \mathrm{~mm}$ teeth is selected to ensure the safety and fast drilling in the bottom of the thick gravel layer. According to the geological environment of Mahu well block, the threepressure profiles of Mahu well block were established for the optimized casing program. The borehole size of each spudding is reduced. The slim hole average ROP was $8.13 \mathrm{~m} / \mathrm{h}$, increased $51.96 \%$ compared to the previous wells. The average drilling period of the slim hole was 55.7 days, saved 24.83 days than the previous wells. The drilling cycle is reduced and the drilling speed is improved.

\section{Acknowledgement}

The authors wish to acknowledge the National Program on General Program of National Natural Science Foundation of China (Contract No. 51474036 and 51204024) for the financial support.

\section{References}

1. Drilling Handbook (Second Edition), drilling handbook compilation group, petroleum industry press, 9 (2013).

2. Reservoir geology. Mark, D., Zuo Bai Ke, petroleum industry press, 1 (2012).

3. Guan Zhichuan, Ke Ke, Su Kanhua. The design method of deepwater drilling well structure. petroleum drilling techniques, 39, (2011): 16-21.

4. Ceng Wei, Wei Qiang, Zhu Xiujuan, et al. Rapid drilling technology for Yingshan formation in Longgang area. drilling and production technology, 34 (2011): 28-31.

5. Yu Jin, Liu Peng, Wu Yicheng, et al. Optimized well structure and drilling fluid technology in the northern block of burning mountain oilfield. Xinjiang Petroleum Science and technology, 2 (2013): 6-8.

6. Yang Yukun. Technique actuality on hole structure design of unconventional series casing and its application foreground in zhungeer basin. Drilling \& production technology, 28 (2005): 1-3.

7. Fan Zhaobin, first, Qi, Yang Shijun. Leak prevention, plugging and pressure control drilling technology for complex igneous rocks in Junggar basin. natural gas industry, 31 (2011): 88-92.

8. Ai Guicheng. Potassium calcium based cationic drilling fluid technology. petroleum drilling and production technology, 29 (2007): 87-88.

9. $\mathrm{Su}$ Peidong, Qin Qirong, Huang Runqiu. Current situation and Prospect of reservoir fracture prediction. Journal of Southwest Petroleum University, 27 (2005): 14-17.

10. Yang Zhibin, Hu Yongzhang, Zhong Jingmin, et al. Influence of engineering geological factors on drilling speed increase. fault block oil and gas field, 17 (2010), 363-365.

11. Halal A S, Warling D J, Wagner R R. Minimum Cost Casing Design. Oil Well, (1996).

12. Hills J O. Design of Casing Programs, Drilling and Production Practice. American Petroleum Institute, (1939).

13. Jeffrey L. Didas. Pipeline Casings - Management of Pipeline Casing Issues. NACE, 9520 (2017)

14. Bleier R. Selecting a Drilling Fluid. Journal of Petroleum Technology; (USA), 42 (1990): 832-834.

15. Sampey J A, Cottingham R. Computer Analysis of Drilling Fluids, Society of Petroleum Engineers, (1980). 